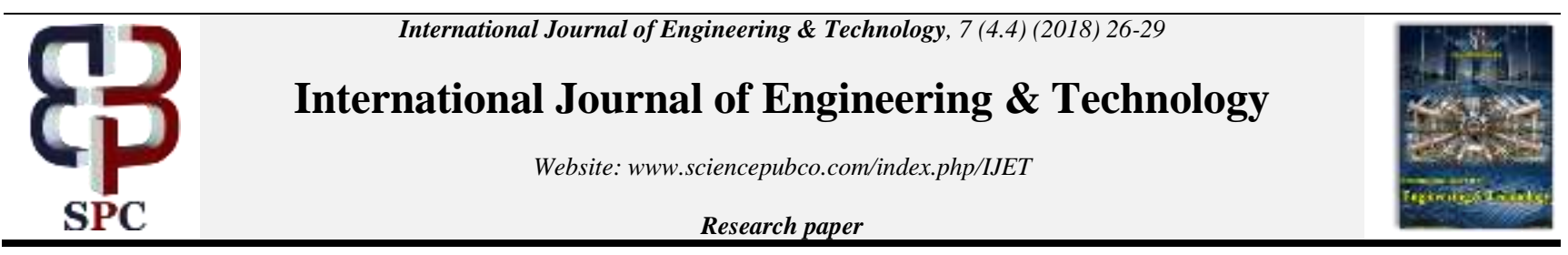

\title{
The Effect of External Technology Cooperation and Internal Relation on Innovative Behavior in Technology Intensive Organizations
}

\author{
Won Il Lee* \\ ${ }^{I}$ Department of Business Administration, Hanbat National University, South Korea \\ *Corresponding author E-mail:tech201@hanbat.ac.kr
}

\begin{abstract}
This study set up a research model based on theoretical research as a study of the effects of external technology cooperation activities and internal relationship competencies on innovation behavior in high technology companies. Based on the research model, hypotheses were set up and tested through questionnaires. The research hypothesis is largely based on the internal and external cooperative activities of companies and the effect of the introduction of open innovation on innovation behavior. H1. The more internal cooperation activities in the enterprise, the more innovative behavior will occur. H2. The more active external cooperation activities within the enterprise, the more innovative behavior will occur. H3. The more internal collaborative activities and external cooperation in the enterprise, the more open innovation will be active. In this paper, I propose that internal cooperative activities, external collaborative activities, and establishment of an open innovation culture are important variables that influence innovation behavior.
\end{abstract}

Keywords: technology, innovative, intensive, innovation,variables

\section{Introduction}

It is difficult to create new product innovation or organizational innovation without employees' innovative behavior under the rapidly changing business environment. Therefore, innovation behavior is directly related to organizational survival (Scott \& Bruce 1994, Subramaniam 2012: and Young, 2012). It is very important to consider the precedent factors of employees' innovative behavior under such management environment(Scott \& Bruce 1994, Subramaniam 2012: and Young, 2012). There are many variables that can influence innovation behavior in an organization, but external technology cooperation activities and internal relations capabilities will influence innovation behavior. This study examines the factors that influence these variables on innovation behavior. This study set up a research model based on theoretical research as a study of the effects of external technology cooperation activities and internal relation competencies on innovation behavior in high technology companies. Based on the research model, hypotheses were set up and tested through questionnaires.

In order to create sustainable competitive advantage for the organization, it is necessary to create continuous innovation behavior(Scott \& Bruce 1994, Subramaniam 2012: and Young, 2012). In order to continuously create innovative behavior, knowledge, resources, and competencies must be exchanged through continuous exchange within and outside the organization. In order to create innovative behaviors that are the source of innovation for companies, it is important to build internal relation activities, external cooperation activities, and open innovation culture.

\section{Literature Review}

\subsection{Innovative Behavior}

Innovative behavior is the act of adopting, spreading and practicing new creative ideas. Innovation behavior is the process of planning a new product through the idea or introduction of an idea, or a new process(Scott \& Bruce 1994, Subramaniam 2012: and Young, 2012). These innovative behaviors are actions that can lead to changes or improvements in new product development or business processes through new ideas at individual, team, and organizational levels(Scott \& Bruce 1994, Subramaniam 2012: and Young, 2012). For the concrete implementation of these ideas, it is possible to pursue collaborative activities at the related individual and team level and to mobilize resources (Scott \& Bruce 1994, Subramaniam 2012: and Young, 2012).

Those who perform these innovative behaviors tend to be creative, challenged, and enterprising, and tend to pursue newness (Scott \& Bruce 1994, Subramaniam 2012: and Young, 2012).

\subsection{External Technology Cooperation}

Gopalakrishnan and Santoro (2004) have statistically verified that organizational structural factors, flexible organizational value factors, trust for partner firms, and support systems influence organizational knowledge transfer and technology transfer.

Shin Dong-yeop and Kwon Sura (2008) pointed out that knowledge, information and resources should be exchanged based on trust for mutually complementary learning in an international joint venture. This refers to the importance of trust in maintaining mutual cooperation between companies. Linda Argote and Paul 
Ingram (2000) emphasized the importance of knowledge transfer to maintain organizational competitiveness. Knowledge within the organization is shared through people, tasks, and various work tools, and this internalization is the organizational competitiveness It is pointed out that the active transfer of knowledge within the organization is making the organization competitive and it is not easy to transfer to the outside. However, it is argued that knowledge transfer helps to strengthen organizational competitiveness because the organization secures competitiveness through knowledge secured within the organization.

\subsection{Internal Technology Cooperation (Internal Relation)}

Vojak, Griffin, Price \&Perlov (2006) analyzed the role of leaders in high technology companies through factor analysis. The role of the leader was defined as a hard driver, a bridge to business world, a technical expert, and an idealist. In this paper, the authors mention that the leaders of high technology companies are not only proficient in technical competence but also mention the importance of external cooperation by referring to the importance of intermediary role in linking with external market. Sapienza(2005) explored the good management and bad management practices of scientists and mentioned the information and technical capabilities, effective communication, and organization management techniques for effective leaders. It is suggested that it is desirable to support the creation of innovation through effective communication within and outside the organization. Borredon and Ingham(2005) emphasized the importance of interactions and communication within the leader's team to promote mentoring and learning in research and development. This interaction emphasizes the diffusion of learning within the organization. Kim, Min, \&Cha(1999) investigated the leaders of high-tech companies in Korea and found that the role of the leader is the role of technical expert, strategic planner, team builder, champion, gatekeeper . The role of the gatekeeper is as follows. First, team leaders play a central role in exchanging technical information outside the team. Second, it is the role of spreading the latest technology and market information to the team members. Third, the team leader is in contact with domestic and international experts and participates in the World Society to obtain and distribute a lot of technical information and ideas. Fourth, it also actively exchanges information with other departments such as production and sales departments. Fifth, efforts are also made to acquire and disseminate customer and market information.

\subsection{Open Innovation}

Gassmann (2006), noted that open innovation is represented by globalization, concentration of technology, convergence of technologies, emergence of new business models, and acceleration of accumulation of knowledge in the enterprise. In addition, the main research on open innovation is pointing out that innovation is centered on globalization, R \& D outsourcing, supplier integration, user innovation, and commercialization of technology. Chesbrough \&Crowther(2006) examined the concept and operation of open innovation in practice. Chesbrough \&Crowther(2006) also looked at the challenges faced by companies adopting open innovation. For this purpose, the author interviewed executives of representative companies in various industries. It is pointed out that in order to realize open innovation, in-bound innovation in connection with external development is needed for actual development and radical innovation. In addition, the challenge facing open innovation innovation is the not-invented syndrome (NIH), which focuses only on internal development. In addition, it can be said that an organization needs initiative for transition to open innovation, support for top management and transition to open innovation.

Witzeman, Slowinski, Dirkx, Gollob\&Miraglia(2006), have shown that firms can meet customer needs through the capacity of internal resources and the capacity of external resources. A stepby-step approach is needed to connect with external resources of the enterprise. This step-by-step approach is firstly cost and supply chain management in terms of cost and infrastructure capability. Second, strategic partnerships are formed to approach customers and markets. Third, building an expanded external network for growth and new ideas. The final step is the formation of an integrated extended network. For innovation capabilities to take advantage of these external technologies, managers need fundamental changes in their thinking. Leadership and cultural management for change are needed to utilize these external competencies. Lichtenthaler\& Ernst (2006) classify the knowledge management of the organization as the acquisition, accumulation, and utilization of knowledge. It is pointed out that this process of knowledge management can be achieved through internal accumulation of knowledge and external acquisitions. The internal and external relations of knowledge management process and knowledge acquisition are classified into $2 * 2$ matrix. In addition to the NIH syndrome (Not-invented Syndrome), which pursues acquisition of knowledge only internally, it has pointed out other organizational cultures. In other words, it is called BI syndrome (Buy-in syndrome), which relies entirely on acquiring knowledge. Also, it is called ASH (All stored syndrome) to accumulate knowledge only inside, and RO (Relate out) to accumulate knowledge outside. It is called OUH (Only use here) to pursue the utilization of knowledge depending on only internal resources and SO (Sold out) to seek the utilization of knowledge outside. In this paper, we extended the existing NIH and pointed out various syndromes that could be in the knowledge management in the organization.

\section{The Methodology and Model}

In this study, the variables affecting innovation behavior are classified into formal and informal networks in terms of external technical cooperation. In the internal dimension, the relationship capacity dimension among internal teams and innovation support system centered on open innovation are examined. In order to create innovative behavior, this study considers new information, knowledge, and capability acquisition through external cooperation based on network perspective. In addition, this study analyzes the effect of exchange of information, knowledge, and competence among active internal teams on innovation behavior. In addition to these external / internal relations, another important part of the organization is the open innovation support system that can support such external / internal cooperation. In this study, I try to derive hypotheses from the viewpoint of network through various literature studies and to carry out empirical studies accordingly.

H1. The more internal relation activities in the enterprise, the more innovative behavior will occur.

H2. The more active external cooperation activities within the enterprise, the more innovative behavior will occur.

H3. The more internal relation activities and external cooperation in the enterprise, the more open innovation will be active.

The definitions of the main variables are as follows and are measured as follows;

\section{External technology cooperation}

External technical cooperation measures how members in an organization are exchanging information, resources, and competence for innovation with the outside. 1. I carry out technical (operational) formal cooperative activities with the outside of the organization. 2. I perform technically (operationally) informal collaborative activities outside the organization. 3. I exchange technical information with the outside of the organization through technical meetings and meetings. 


\section{Internal technology cooperation (internal relation)}

Internal technology cooperation measures the extent to which internal resources are exchanging information, resources and capabilities within an organization for innovation. 1. I perform technical (operational) formal cooperative activities within the organization. 2. I conduct technical (operational) informal cooperative activities within the organization. 3. I exchange technical information through technical meetings and meetings within the organization.

\section{Open Innovation}

Open innovation measures the degree to which an open culture for open innovation in an organization is built. 1. Our company has a culture of continuously communicating technical information, resources, and competence with the outside. 2. Our company has procedures for external and cooperation. 3. 2. Our company has a system for external and cooperation. 3. Our company strongly encourages the use of external technology as well as its own technology for technology development.

Innovation Behavior

Innovation behavior is measured by the creation, diffusion, and adoption of new ideas in product or process improvement. 1. I draw new ideas about difficult issues. 2. I find a new solution to solve the problem. 3. I systematically introduce new ideas into my work environment.

The hypotheses presented in this study were verified and the survey method was used for the empirical study of the researchers. The questionnaire consisted of 30 items, including internal cooperative activities, external collaborative activities, open innovation culture, innovative behavior, and demographic variables in the questionnaire. . The survey was conducted for venture companies in Daejeon from September to October, 2016. A total of 200 questionnaires were distributed and 152 were collected. 140 questions were used for statistical analysis except for the questionnaires.

Data collected through questionnaires were analyzed statistically using SPSS 20.0. Reliability analysis and validity analysis were performed. Correlation analysis and multiple regression analysis were conducted to verify the relationship between independent variables and dependent variables.

\section{The Findings}

The demographic characteristics of the study sample are as follows. First, 101 men (72.1\%) and 39 women (27.9\%) are. Second, the number of years of service was $9(6.4 \%)$ for less than 1 year, $63(45 \%)$ for less than 3 years, $40(28.6 \%)$ for 3 years and less than 5 years, more than 5 years to less than 10 years $21(15.0 \%)$ and $7(4.4 \%)$ for more than 10 years. Third, in the field of business, there were $13(9.3 \%)$ planning / management, 57 manufacturing (40.7\%), 38 marketing/ sales (27.1\%), 14 research (10\% 12.9\%).A reliability analysis is conducted to find out how consistent the questionnaire items used as measurement tools are. Reliability is a concept that can be expressed as stability, predictability, accuracy, dependability, etc., meaning that results are comparable when measuring objects by comparable independent measurement methods. The reliability analysis results of this study are shown in the following table.

Table. 1: Factor Analysis and Reliability for Internal Networks and External Networks

\begin{tabular}{|l|l|l|l|}
\hline Variables & EX Net & IN Net & \multirow{2}{*}{ Cronbach' $\alpha$} \\
\hline IN_Net 1 & .203 & .826 & \\
\cline { 1 - 2 } IN_Net 2 & .309 & .793 & \multirow{2}{*}{.886} \\
\hline IN_Net 3 & .231 & .747 & \\
\hline IN_Net 4 & .219 & .806 & \\
\hline IN_Net 5 & .140 & .835 & \\
\hline
\end{tabular}

\begin{tabular}{|c|c|c|c|}
\hline EX Net 1 & .782 & .379 & \multirow{5}{*}{.929} \\
\hline EX Net 2 & .862 & .232 & \\
\hline EX Net 3 & .832 & .264 & \\
\hline EX Net 4 & .895 & .194 & \\
\hline EX Net 5 & .877 & .143 & \\
\hline
\end{tabular}

[Table. 2]: Factor Analysis and Reliability for Open Innovation

\begin{tabular}{|l|l|l|}
\hline Variables & Open Innovation & Cronbach' $\alpha$ \\
Open Inno. 1 & .929 & \\
Open Inno. 2 & .911 & \multirow{2}{*}{.927} \\
Open Inno. 3 & .901 & \\
\hline Open Inno. 4 & .888 & \\
\hline
\end{tabular}

[Table. 3]: Factor Analysis and Reliability for Innovative Behavior

\begin{tabular}{|l|l|l|}
\hline Variables & Innovative Behavior & Cronbach' $\alpha$ \\
\hline INNO_BEHA1 & .935 & \multirow{2}{*}{.907} \\
\hline INNO_BEHA2 & .889 & \\
\hline INNO_BEHA3 & .931 & \\
\hline
\end{tabular}

The results of the correlation analysis between the variables are as follows. The results show that internal cooperative activities, external collaborative activities, and open innovation cultures have a significant correlation with innovative behavior of .05 or more. Correlation between these variables was later re-verified through regression analysis.

\begin{tabular}{|c|c|c|c|c|c|c|}
\hline & Average & STD & IN NET & $\begin{array}{l}\text { EX } \\
\text { NET }\end{array}$ & $\begin{array}{l}\text { OPEN } \\
\text { INNO }\end{array}$ & $\begin{array}{l}\text { INNO } \\
\text { BEHA }\end{array}$ \\
\hline IN NET & 3.3729 & .82766 & 1 & $.518^{* *}$ & $.356^{* *}$ & $.630 * *$ \\
\hline EX NET & 3.3929 & .87274 & $.518^{* *}$ & 1 & $.412 * *$ & $.588 * *$ \\
\hline $\begin{array}{l}\text { OPEN } \\
\text { INNO }\end{array}$ & 3.8125 & .79518 & $.356 * *$ & $.412 * *$ & 1 & $.381 * *$ \\
\hline $\begin{array}{l}\text { INNO } \\
\text { BEHA }\end{array}$ & 3.4857 & .86070 & $.630 * *$ & $.588 * *$ & $.381 *$ & 1 \\
\hline
\end{tabular}

$*: \mathrm{p}<0.05, * *: \mathrm{p}<0.01$

Internal cooperative activities, and external collaborative activities on innovative behaviors. The effect of internal cooperative activities on innovative behavior was $p=.000$. For the effect of external collaborative activities on the innovative behavior, the $\mathrm{p}$ value was $\mathrm{p}=.000$. All of them were at the level of significance. Adjusted $\mathrm{R}$ Square .483 indicates that the regression equation has explanatory power. Collinearity Statistics was also Tolerance limits .732 and VIF 1.350. Through this, H1. The more internal cooperation activities in the enterprise, the more innovative behavior will occur. $\mathrm{H} 2$. The more active external cooperation activities within the enterprise, the more innovative behavior will occur. Hypothesis 1 and Hypothesis 2 were verified.

[Table. 5]: Regression Analysis for external technology cooperation, internal relation and innovative behavior

\begin{tabular}{|c|c|c|c|c|c|c|}
\hline & $\begin{array}{l}\text { Non- } \\
\text { standardized } \\
\text { coefficients }\end{array}$ & BETA & $\begin{array}{l}\mathrm{T} \\
\text { Value }\end{array}$ & $\begin{array}{l}P \\
\text { Value }\end{array}$ & \multicolumn{2}{|c|}{$\begin{array}{l}\text { Collinearity Statis } \\
\text { tics }\end{array}$} \\
\hline Constant & .246 & & 2.963 & .004 & $\begin{array}{l}\text { Tolerance } \\
\text { limits }\end{array}$ & VIF \\
\hline IN NET & .074 & .445 & 6.239 & .000 & .732 & 1.366 \\
\hline \multirow[t]{2}{*}{ EX NET } & .070 & .358 & 5.025 & .000 & .732 & 1.366 \\
\hline & \multicolumn{6}{|c|}{$\begin{array}{l}\mathrm{R}=.701, \mathrm{R} \text { Square }=.491, \text { Adjusted } \mathrm{R} \text { Square } .483 \\
\mathrm{~F}=66.008, \mathrm{p}=0.000, \text { Durbin- } \text { Watson }=2.251\end{array}$} \\
\hline
\end{tabular}

Internal cooperative activities, and external collaborative activities on open innovation culture. The effect of internal cooperative activities on open innovation culture was $p=.031$. For the effect of external collaborative activities on the open innovation culture, 
the $\mathrm{p}$ value was $\mathrm{p}=.001$. All of them were at the level of significance. Adjusted R Square 186 indicates that the regression equation has explanatory power. Collinearity Statistics was also Tolerance limits .732 and VIF 1.366. H3. The more internal collaborative activities and external cooperation in the enterprise, the more open innovation will be active. Hypothesis 3 was verified.

[Table. 6]: Regression Analysis for external technology cooperation, internal relation and open innovation

\begin{tabular}{|c|c|c|c|c|c|c|}
\hline \multirow[b]{2}{*}{ Constant } & \multirow{2}{*}{$\begin{array}{l}\text { Non- } \\
\text { standardized } \\
\text { coefficients } \\
.285\end{array}$} & \multirow[t]{2}{*}{ BETA } & \multirow{2}{*}{$\begin{array}{l}\mathrm{T} \\
\text { Value } \\
7.790\end{array}$} & \multirow{2}{*}{$\begin{array}{l}\mathrm{P} \\
\text { Value } \\
.000\end{array}$} & \multicolumn{2}{|c|}{$\begin{array}{l}\text { Collinearity Statis- } \\
\text { tics }\end{array}$} \\
\hline & & & & & $\begin{array}{l}\text { Tolerance } \\
\text { limits }\end{array}$ & VIF \\
\hline IN NET & .086 & .194 & 2.173 & .031 & .732 & 1.366 \\
\hline EX NET & .081 & .312 & 3.483 & .001 & .732 & 1.366 \\
\hline & \multicolumn{6}{|c|}{$\begin{array}{l}\mathrm{R}=.444, \mathrm{R} \text { Square }=.198, \text { Adjusted R Square } .186 \\
\mathrm{~F}=16.866, \mathrm{p}=0.000, \text { Durbin- Watson }=1.656\end{array}$} \\
\hline
\end{tabular}

\section{Summary and Conclusions}

The purpose of this study was to investigate the effect of external technology cooperation activities and internal relationship competence on innovation behaviors in technology intensive organizations. In today's fast-changing and highly competitive environment, the innovation behavior of employees is an essential element in creating business performance. Companies must continually release new products and these new products are the result of newly proposed innovations based on the creative innovation behavior of the organization members. Organizations that continuously perform innovation behavior within an organization will continue to generate and grow competitive advantage, but organizations with minimal innovation behavior in the organization will be unable to maintain their competitive advantage. In spite of the importance of these innovative behaviors, in-depth research on the determinants of innovation behavior is lacking. In this study, I have examined the determinants of innovation behavior from the viewpoint of network in the context of external technology cooperation activities, internal relationship capacity building, and open innovation to support them. In order to stimulate innovation behavior in the context of the current emphasis on open innovation, it is important to build internal cooperation activities, external cooperation activities, and open innovation culture.

This paper is considered to have great significance in terms of academic and practical

In the context of emphasizing open innovation, this thesis has a great academic significance because it has developed the existing network viewpoint in connection with innovation. This study provides a practical implication to establish an open innovation culture as well as internal and external cooperation activities in order to induce innovation behavior, thus providing a great implication for top management's organizational management.

\section{Acknowledgement}

This research was supported by the research fund of Hanbat National University in 2016.

\section{References}

[1] Argote, L., \& Ingram, P. 2000, Knowledge transfer: A basis for competitive advantage in firms. Organizational behavior and human decision processes, Vol. 82, No. 1, pp. 150-169.

[2] Borredon, L., \& Ingham, M. 2005, Mentoring and organisational learning in research and development. R\&D Management, Vol. 35, No. 5, pp. 493-500.
[3] Chesbrough, H., \& Crowther, A. K. 2006, Beyond high tech: early adopters of open innovation in other industries. R\&D Management, Vol. 36, No. 3, pp. 229-236.

[4] Gassmann, O. 2006, Opening up the innovation process: towards an agenda. R\&D Management, Vol. 36, No. 3, pp. 223-228.

[5] Gopalakrishnan, S., \& Santoro, M. D. 2004, Distinguishing between knowledge transfer and technology transfer activities: The role of key organizational factors. IEEE transactions on Engineering Management, Vol. 51, No. 1, pp. 57-69.

[6] Kim, Y., Min, B., \& Cha, J. 1999, The roles of R\&D team leaders in Korea: a contingent approach. R\&D Management, Vol. 29 No. 2, pp. 153-166.

[7] Sapienza, A. M. 2005, From the inside: scientists' own experience of good (and bad) management. R\&D Management, Vol. 35, No. 5, pp. 473-482.

[8] Scott, S. G., \& Bruce, R. A. 1994, Determinants of innovative behavior: A path model of individual innovation in the workplace. Academy of management journal, Vol. 37, No.3, pp. 580-607.

[9] Subramaniam, I. D. 2012, Determinant of innovative behavior in the workplace: A case study of a Malaysian public sector organisation. American Journal of Social Issues and Humanities, Vol. 2, No. 6, pp.384-397.

[10] Shin Dong yeop, \& Kwon Sura. 2008, Learning dilemma and trust between partner companies in international joint ventures. Strategic Management Research, Vol. 11, No. 2, pp. 21-59.

[11] Vojak, B. A., Griffin, A., Price, R. L., \&Perlov, K. 2006, Characteristics of technical visionaries as perceived by American and British industrial physicists. R\&D Management, Vol. 36, No. 1, pp.17-26.

[12] Young, L. D. 2012, How to promote innovative behavior at work? The role of justice and support within organizations. The Journal of creative behavior, Vol. 46 No. 3, pp.220-243.

[13] Witzeman, S., Slowinski, G., Dirkx, R., Gollob, L., Tao, J., Ward, S., \&Miraglia, S. 2006, Harnessing external technology for innovation. Research-Technology Management, Vol. 49, No. 3, pp. 19-27. 